\title{
IMPLANTAÇÃO DE TERAPIA COMUNITÁRIA ONLINE: TECNOLOGIA DO CUIDADO EM TEMPOS DE PANDEMIA
}

\author{
IMPLEMENTACIÓN DE LA TERAPIA COMUNITARIA EN LÍNEA: TECNOLOGÍA \\ DE ATENCIÓN EN TIEMPOS DE PANDEMIA
}

\section{IMPLEMENTATION OF ONLINE COMMUNITY TERAPY: CARE TECHNOLOGY IN TIMES OF PANDEMIC}

\author{
André Luiz Pereira SILVA ${ }^{1}$ \\ Doralice OTAVIANO ${ }^{2}$ \\ Fernanda Cruz Vieira FERREIRA ${ }^{3}$ \\ Jurema Valkiria OTAVIANO ${ }^{4}$ \\ Jussara OTAVIANO ${ }^{5}$ \\ Neusa OLIVEIRA ${ }^{6}$ \\ Wellington Palmieri DONIZETE ${ }^{7}$
}

RESUMO: De repente em março de 2020 nos vimos confinados e isolados em nossos lares, em função uma crise sanitária global advinda de uma pandemia, causada pela contaminação de um vírus chamado COVID-19. Esta crise sanitária, gerou também, uma crise nos determinantes sociais da saúde, principalmente os ligados à economia, a educação e a cultura. Mas também gerou uma outra crise, a psicossocial, onde populações atingidas pelos efeitos dos danos mentais causados pela pandemia e situação de isolamento, apresentaram sinais importantes de estresse. É neste cenário que a Terapia Comunitária Integrativa, até então realizada presencialmente, se renova e se reinventa. Este artigo relata a experiência de implantação da Terapia Comunitária Integrativa online no Brasil e apresenta os resultados do Polo Afinando vidas na contribuição da melhoria da qualidade vida e da saúde mental individual e coletiva da população brasileira.

1 Instituto Afinando Vidas, São Paulo - SP - Brasil. Psicólogo e Terapeuta Comunitário. ORCID:
https://orcid.org/0000-0003-2641-1281. E-mail: a_luizp@yahoo.com.br
${ }^{2}$ Associação Paulista para o Desenvolvimento da Medicina - Hospital São Paulo SPDM/HSP, São Paulo - SP -
Brasil. Psicóloga no programa Recomeço Família e Coordenadora do curso de Terapia Comunitária no Instituto
Afinando Vidas. Doutora em Terapia Familiar pela International Corporate University (I.C.U./CAIFCOM).
ORCID: https://orcid.org/0000-0002-6099-6765. E-mail: doramusicoterapia.otaviano@gmail.com
3 Instituto Afinando Vidas, São Paulo - SP - Brasil. Psicóloga e Terapeuta Comunitária. ORCID:
https://orcid.org/0000-0001-8569-7182. E-mail: fnanda25@hotmail.com
${ }^{4}$ Instituto Afinando Vidas, São Paulo - SP - Brasil. Terapeuta Comunitária. Mestrado em Bioética (USC).
ORCID: http://orcid.org/0000-0002-1999-2308. E-mail: arvoregrande2000@yahoo.com.br
${ }^{5}$ Universidade Anhembi Morumbi (UAM), São Paulo - SP - Brasil. Docente do Departamento de Ciências da
Saúde. Mestrado em Educação (UNIBAN). ORCID: https://orcid.org/0000-0002-4914-393X. E-mail:
jussara.otaviano@gmail.com
${ }^{6}$ Instituto Afinando Vidas, São Paulo - SP - Brasil. Assistente social e Psicóloga Terapeuta de Família e Terapeuta
Comunitária. ORCID: https://orcid.org/0000-0003-2625-2161. E-mail: neusadeoliveira@terra.com.br
${ }^{7}$ Universidade Anhanguera de São Paulo (UNIAN), São Paulo - SP - Brasil. Graduando no curso de Psicologia
e Terapeuta Comunitário no Instituto Afinando Vidas. ORCID: https://orcid.org/0000-0002-6044-4629. E-mail:
wellingtonrock379@gmail.com 
PALAVRAS-CHAVE: Terapia comunitária integrativa online. Tecnologia em saúde. Cuidado coletivo humanizado. Inovação.

RESUMEN: De repente en marzo de 2020 nos encontramos confinados y aislados en nuestros hogares, debido a una crisis de salud global derivada de una pandemia, provocada por la contaminación de un virus llamado COVID-19. Esta crisis de salud también generó una crisis en los determinantes sociales de la salud, especialmente los relacionados con la economía, la educación y la cultura. Pero también generó otra crisis, la psicosocial, donde las poblaciones afectadas por los efectos del daño psíquico provocado por la pandemia y el aislamiento, mostraron importantes signos de estrés. Es en este escenario donde se renueva y reinventa la Terapia Comunitaria Integrativa, previamente realizada de manera presencial. Este artículo informa sobre la experiencia de implementación de la Terapia Comunitaria Integrativa en línea en Brasil y presenta los resultados del Polo Afinando Vidas en la contribución de mejorar la calidad de vida y la salud mental individual y colectiva de la población brasileña.

PALABRAS CLAVE: Terapia comunitaria integrativa en línea. Tecnología de la Salud. Atención colectiva humanizada. Innovación.

ABSTRACT: Suddenly in March 2020 we found ourselves confined and isolated in our homes, due to a global health crisis arising from a pandemic, caused by the contamination of a virus called COVID-19. This health crisis also generated a crisis in the social determinants of health, especially those related to the economy, education and culture. But it also generated another crisis, the psychosocial crisis, where populations affected by the effects of mental damage caused by the pandemic and isolation, showed important signs of stress. It is in this scenario that the Integrative Community Therapy, previously carried out in person, is renewed and reinvented. This article reports on the experience of implementing the Integrative Community Therapy online in Brazil and presents the results of the Afinando Vidas Pole in the contribution of improving the quality of life and the individual and collective mental health of the Brazilian population.

KEYWORDS: Online integrative community therapy. Health technology. Humanized collective care. Innovation.

\section{Introdução}

O mundo de repente se depara com um cenário nunca antes enfrentado, uma pandemia, a do COVID-19, alastrando e atingindo a maioria dos países em proporções imensas. Segundo Daumas et al. 2020 a COVID-19 é uma pandemia em curso, trata-se de uma doença sistêmica, altamente contagiosa, com um grau de letalidade 14 vezes maior que o da influenza. Dependendo das variações organizacionais, culturais e sociais de cada continente/país, pode ser tornar devastadora em função de sua forma mais grave que é a respiratória aguda (Severe Acute Respiratory Syndrome - SARS-CoV-2) esta doença somada a indisponibilidade de leitos 
intensivos tem sido responsável pelo alto índice de mortalidade no Brasil e em outros países (DAUMAS et al., 2020).

A doença foi identificada pela primeira vez em Wuhan, na província de Hubei, República Popular da China, em 01 de dezembro de 2019, mas o primeiro caso foi reportado em 31 de dezembro do mesmo ano. Em 12 de março de 2020, a Organização Mundial De Saúde declarou emergência mundial por causa do surto e classificou a situação de saúde como pandemia o mais alto índice de emergência em saúde pública.

De acordo com a OMS, até 31 de agosto de 2020 foram confirmados no mundo 25.118.689 casos de COVID-19 (264.107 novos em relação ao dia anterior) e 844.312 mortes (5.385 novas em relação ao dia anterior), sendo que na região das Américas, cerca de 13.268.684 casos confirmados e 465.206 mortes. Dentre os países que lideram a quantidade de surtos estão os Estados Unidos, cerca de 5.624.449 casos e 175.076 mortes, e Brasil, com cerca de 3.532.330 casos e 113.358 mortes (OMS 2020).

Figura 1 - Casos confirmados de coronavírus no mundo estão próximos de 20 milhões, e subindo rapidamente (gráfico)

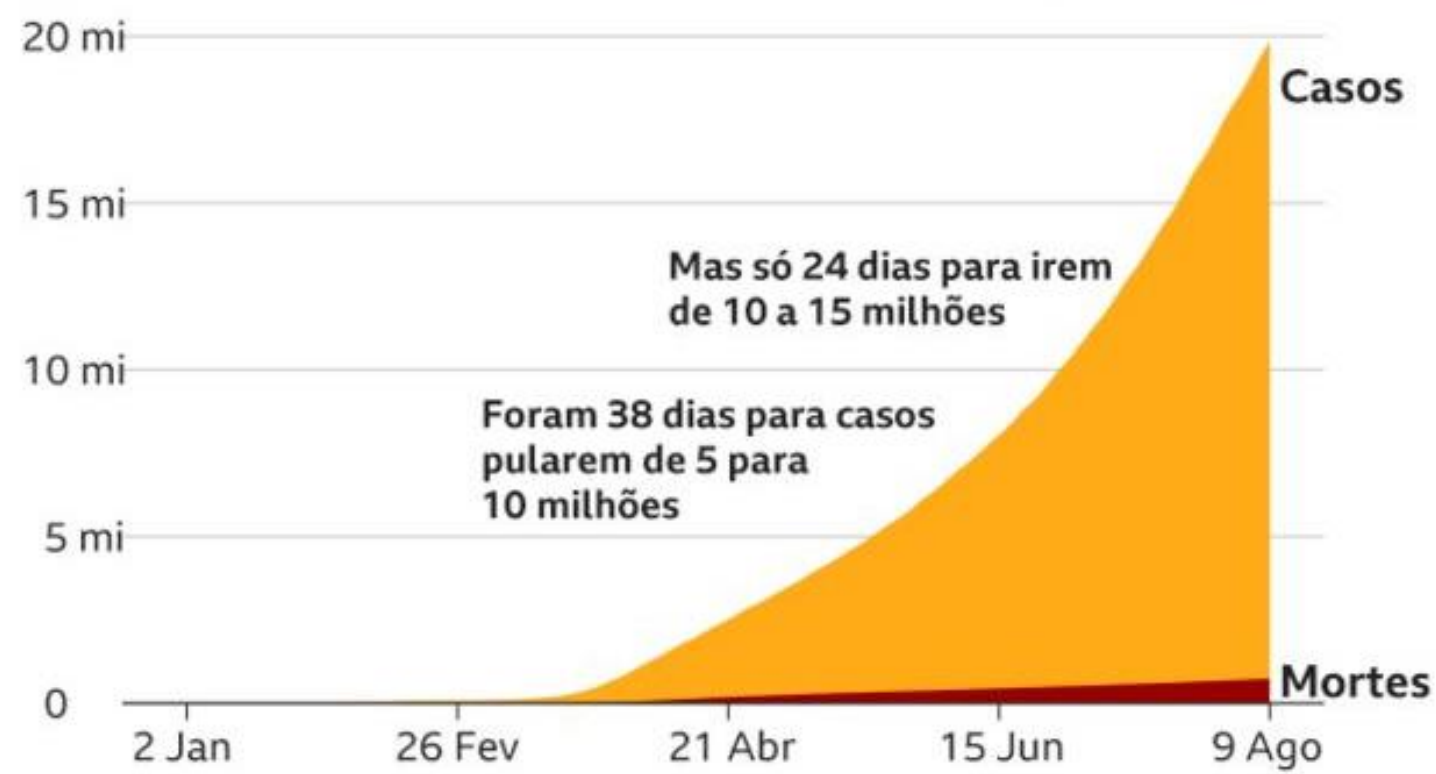

Fonte: Johns Hopkins University $(2020)^{8}$

8 Johns Hopkins University, agências nacionais de saúde, dados até 9 de agosto de 2020. Disponível em: https://www.bbc.com/portuguese/internacional-53734786. Acesso em: 2 set. 2020.

Temas em Educ. e Saúde, Araraquara, v. 16, n. esp. 1, p. 393-408, set., 2020. 
Figura 2 - Gráfico Mortes no mundo por COVID-19 até agosto de 2020

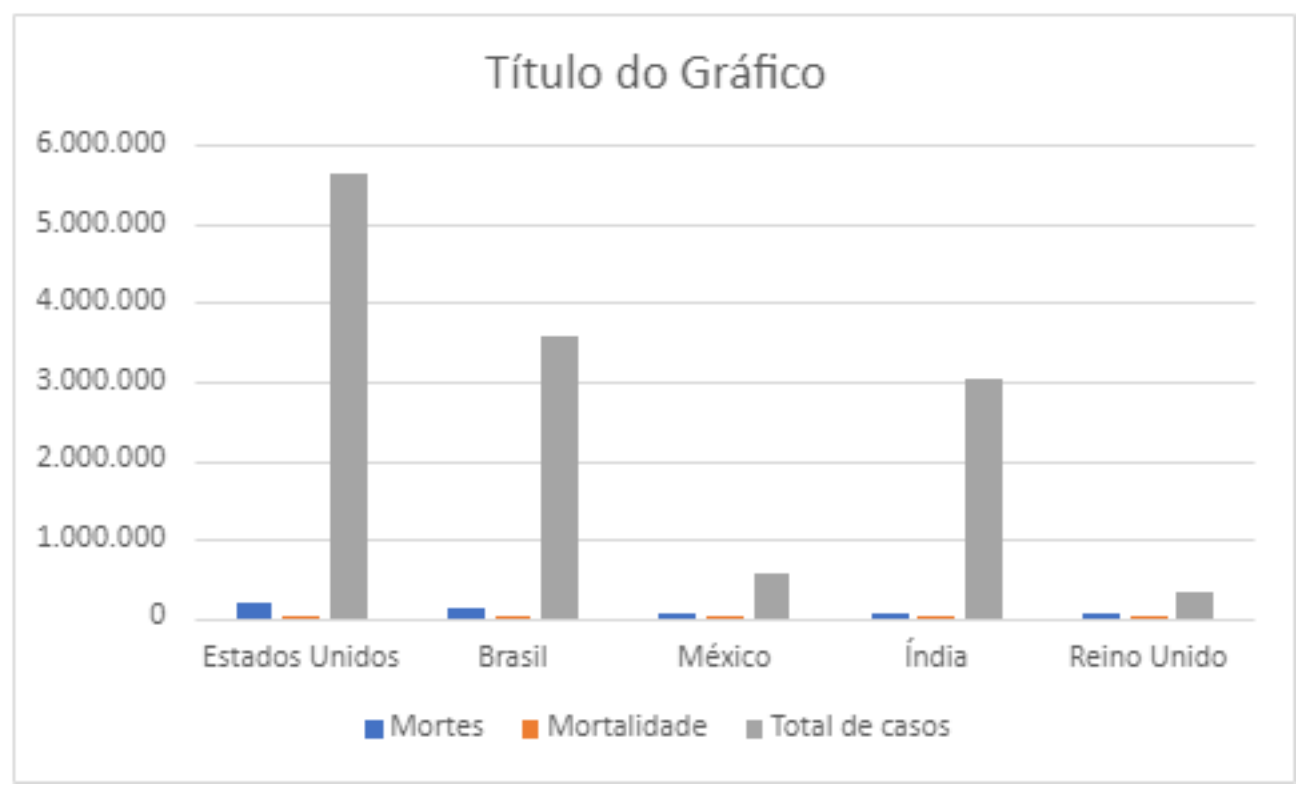

Fonte: BBC News Brasil (2020) - adaptado pelos autores

A história das pandemias na humanidade é registrada de longa data, mas quando o evento se apresenta o mesmo vem acompanhado da necessidade de adaptações emergenciais, mudança nas dimensões econômicas, política e principalmente na saúde. Historicamente esses eventos aparecem em manuscritos bíblicos e atravessam os séculos e as décadas até nos encontrar. Vem costumeiramente associado ao desconhecimento das pessoas sobre o impacto dessas doenças nas relações sociais.

Doenças com estas características são capazes de dizimar milhões de pessoas. Observando a linha do tempo destes acontecimentos, identificam-se registros de várias doenças contagiosas muito antes e depois da Era Cristã, a saber:

Quadro 1 - Registros de doenças contagiosas antes e depois da Era Cristã

\begin{tabular}{|l|l|}
\hline Doenças & Conceito \\
\hline A Peste do século III & $\begin{array}{l}\text { Nos idos de 251 á 266 D.C. oriunda do Egito que se } \\
\text { espalhou para Grécia, norte da África, devastando todo o } \\
\text { Império Romano; }\end{array}$ \\
\hline A Peste negra do Séc. XIV & $\begin{array}{l}\text { Uma das mais trágicas da história, iniciando-se na Ásia } \\
\text { menor atravessando China e Mongólia, dizimando um } \\
\text { terço da Europa, provocando aproximadamente 200 } \\
\text { milhões de mortes. }\end{array}$ \\
\hline A Gripe ou Peste Espanhola, & $\begin{array}{l}\text { No Século XX, por volta da época da primeira grande } \\
\text { guerra, entre os anos de 1918 e 1919, causada pela } \\
\text { mutação do vírus Influenza que repete a contaminação, } \\
\text { mas com tamanho menor em 2009, que matou mais de 50 } \\
\text { milhões de pessoas; }\end{array}$ \\
\hline Ebola (2013-2016) & $\begin{array}{l}\text { Este vírus foi identificado no Sudão e República } \\
\text { Democrática do Congo, sendo letal em humanos e } \\
\text { animais. O surto epidêmico aconteceu em 2013 na região }\end{array}$ \\
\hline
\end{tabular}




\begin{tabular}{|l|l|}
\hline & $\begin{array}{l}\text { da África Ocidental atingindo países como Serra Leoa, } \\
\text { Libéria e Guiné, infectando 28.454 pessoas e matando } \\
11.297 .\end{array}$ \\
\hline SARS-Cov-2 & $\begin{array}{l}\text { Anteriormente citada com características que se } \\
\text { assemelham à gripe e a transmissão que ocorre de para } \\
\text { pessoa através do contato de gotículas. Embora alguns } \\
\text { medicamentos e vacinas estejam sendo testados, a ciência } \\
\text { ainda não descobriu uma maneira eficaz para combater a } \\
\text { doença de alcance mundial. }\end{array}$ \\
\hline
\end{tabular}

Fonte: Rezende (2009), Ornell (2020) e Super Interessante (2004)

Um cenário de pandemia suscita muitas reflexões, pois requer mudanças que nem sempre são fáceis ou, tão pouco, rápidas. A humanidade fez importantes aprendizados com as pandemias do passado, esse resultado foi o aprimoramento da ciência em pesquisas, em técnica, segurança, qualidade e investimento em profissionais de saúde e no desempenho de suas ações. Embora muito tenha que ser feito para que esse status se torne excelente (SANAR, 2020; ECCARD, 2018).

A experiência de isolamento que estamos vivendo com a pandemia do COVID 19 tem revelado situações que requerem cuidados específicos, entre eles a manutenção da Saúde Integral, destacando a importância para os cuidados de prevenção da qualidade da Saúde Mental (SHIGEMURA et al., 2020; CRISTOPH, 2010).

Estudos atuais e organizações de saúde têm chamado a atenção para o impacto que esta pandemia tem trazido, apontando inclusive na segunda pandemia - o medo. Recomendações são feitas para que as sociedades em situação de confinamento procurem estratégias para manter um corpo e mentes saudáveis.

\section{O comprometimento da qualidade da saúde mental individual e coletiva devido a pandemia}

As Agências Nacionais e Internacionais de Saúde têm recomendado ações preventivas que colaborem com o bloqueio da disseminação da COVID-19 no Brasil, evitando o aumento de mortes e o agravamento no Sistema de Saúde. O isolamento social é umas das estratégias mundiais mais importantes dessas ações, contudo o isolamento social tem causado desconforto psicológico para muitas pessoas, despertando ansiedade, estresse e medo (SHALDERS, 2020).

Para entender as repercussões psicológicas de uma pandemia, parte-se do ponto que as emoções envolvidas, como medo e raiva, devem ser consideradas e observadas.

O medo é um mecanismo de defesa animal adaptável que é fundamental para a sobrevivência e envolve vários processos biológicos de preparação para uma resposta a eventos potencialmente ameaçadores. No entanto, quando é frequente, sem pausas para a recuperação, 
para que a homeostase ocorra, torna-se prejudicial e pode ser um componente essencial no desenvolvimento de vários transtornos psiquiátricos. Em uma escala de mensuração de 9-10 em uma pandemia, o medo aumenta os níveis de ansiedade e estresse em indivíduos saudáveis e intensifica os sintomas daqueles com transtornos psiquiátricos preexistentes (CORREA, 2020).

De acordo com Correa (2020) durante as pandemias, o número de pessoas cuja saúde mental é afetada tende a ser maior que o número de pessoas afetadas pela doença. Outras tragédias ocorridas no mundo mostraram que as implicações para a saúde mental podem durar mais tempo e ter maior prevalência que a própria pandemia (MORENS et al., 2008; REARDON, 2015).

Além da experiência constante do medo da morte, a pandemia do COVID-19 trouxe impactos e necessidades de adequações e adaptações em diferentes esferas como na organização familiar, na educação, nas empresas e locais públicos. Exigência de respostas rápidas na rotina pessoal e de trabalho, aliadas à necessidade de isolamento, contribuem para a presença permanente e persistente de sentimentos de desamparo e abandono, além de poder aumentar a insegurança devido às repercussões econômicas e sociais oriundas dessa tragédia.

Para Correa (2020), o medo tem como função básica a preservação da vida, objetiva antecipar o dano físico ou psicológico e também social, gerando comportamentos de luta-fuga ou de "congelamento", evidenciado na paralisação do indivíduo, diante do fenômeno que desperta o medo (CORREA, 2020).

O medo também é um dos responsáveis pela acumulação da ansiedade e estresse. Anatomicamente nosso cérebro, diante de situações que provocam medo, atua da seguinte forma: Toda a informação que entra através dos sentidos passa pela amígdala, uma estrutura muito pequena do nosso sistema límbico que constitui a área mais antiga do cérebro, regulada exclusivamente pelas nossas emoções. A amígdala monitora o que acontece em nosso interior e exterior e diante destas situações, o seu sistema de alerta ativa imediatamente o sistema nervoso, para que ele coloque rapidamente em pratica uma resposta: a luta, a fuga ou o congelamento (CRISTOPH, 2010).

O acometimento mental na população pela pandemia da COVID -19, não se restringe apenas à zona de epicentro da doença. A população espanhola também compartilhou a piora na saúde mental experimentada pelos chineses. Quase um quinto da população espanhola entrevistada apresentou-se depressiva, e 21\% ansiosa (OMS, 2020).

Os sintomas de estresse e transtorno do estresse pós-traumático nessa população foram observados em três vezes mais pessoas do que na população geral em condições normais (OMS, 2020). Uma pesquisa francesa vai além e associa esse aumento na incidência de distúrbios 
psiquiátricos durante a pandemia SARS em 2003 a um aumento significativo nos casos de suicídio em pessoas com 65 anos ou mais que estavam em isolamento na época. No entanto para Almeida, para combater essa crise sanitária mental, é necessário conhecer seus principais sinais, para que a população possa receber o auxílio necessário o quanto antes (ALMEIDA, 2020).

\section{A importância da Terapia Comunitária em tempos de pandemia}

A Terapia Comunitária Integrativa é uma prática terapêutica brasileira cuja missão é integrar o conhecimento científico e a sabedoria popular com o objetivo de buscar soluções para conflitos e sofrimentos humanos. De acordo com o próprio autor da técnica, Barreto, a Terapia Comunitária Integrativa é um instrumento que nos permite construir redes sociais solidárias de promoção da vida e mobilizar os recursos e as competências dos indivíduos, das famílias e das comunidades. Procura suscitar a dimensão terapêutica do próprio grupo valorizando a herança cultural dos nossos antepassados indígenas, africanos, europeus e orientais, bem como o saber produzido pela experiência de vida de cada um (BARRETO, 2019).

A roda de Terapia Comunitária Integrativa é uma técnica utilizada em grupos: escolas, empresas, comunidades, equipes de trabalhos entre outros. Essa técnica foi criada pelo etnopsiquiatra brasileiro Professor Doutor Adalberto Barreto e é praticada em mais de 24 países entre América do Sul, Europa e África. O Brasil atualmente desenvolve esta prática a partir de seus quarenta e dois Polos de Formação, os quais ministram cursos e realizam rodas.

A formação em Terapia Comunitária Integrativa contempla vivências práticas, conteúdos teóricos, acompanhamento sistemático aos alunos em formação (intervisão), assim como reflexão e apreciação sobre as rodas por eles realizadas, possibilitando que os mesmos se apropriem da técnica, se sentindo seguros para realizarem as rodas (BARRETO et al., 2020).

Computa-se mais de 30.000 terapeutas comunitários pelo Brasil afora, estes dados são organizados e fornecidos pela ABRATECOM - Associação Brasileira de Terapia Comunitária Integrativa, órgão regulador desta prática (ABRATECOM, 2020).

A Terapia Comunitária Integrativa está inserida na Política Nacional de Práticas Integrativas e complementares (PNPIC) desde 2018, atuando em áreas como: saúde, educação, assistência social, comunidades e setor privado (BRASIL, 2018).

Também a Terapia Comunitária Integrativa se fez presente em situações de catástrofes e acidentes socioambientais, como Brumadinho, pelo Polo Afinando Vidas em 2019 e deslizamentos em comunidades localizadas na baixada santista - 2020, mostrando-se uma 
técnica eficiente e assertiva no acolhimento das pessoas que sofreram com essas catástrofes, assim como para os funcionários que atenderam estas populações.

\section{Implantação da Terapia Comunitária Integrativa Online}

Em fevereiro de 2020, quando surgiu o primeiro caso de COVID-19 na cidade de São Paulo, e com os anúncios dos órgãos oficiais sobre a transmissão comunitária da doença e a necessidade do isolamento social, alguns países simultânea e sincronicamente tiveram ideias e práticas de enfrentamento à situação de crise mundial. Bélgica, e seguidamente Chile e Brasil testaram a realização de rodas de Terapia Comunitária Integrativa no ambiente virtual (ALVES, 2020).

No Brasil, o Polo Formador em Terapia Comunitária Integrativa Afinando Vidas, realizou sua primeira roda online no dia 19 de março de 2020. Iniciou essa ação como experimento primeiramente com sua equipe de trabalho, seus formadores, a fim de verificar a viabilidade de desenvolver essa prática, no intuito de contribuir para o acolhimento do sofrimento humano nesse contexto da pandemia. Após reflexões e apreciações, a equipe descreveu a técnica de trabalho que desenvolveu e observou o quanto essa ação poderia ser realizada e ampliada. Essa experiência foi replicada para outros Polos Formadores, assim como para ABRATECOM, levando a criação conjunta de um protocolo, que sistematiza a realização de rodas de terapia comunitária integrativa online.

De acordo com a OMS, Tecnologia em saúde é compreendida como um conjunto de ferramentas, entre elas de trabalho, que põem em movimento uma ação transformadora da natureza. Sendo que, além dos equipamentos, devem ser incluídos os conhecimentos e ações necessárias para operar essa ação. São recursos materiais e imateriais dos atos técnicos e dos procedimentos de trabalho. O termo "Tecnologia em Saúde" abrange, então, um conjunto de aparatos com o objetivo de promover a saúde, prevenir e tratar as doenças e reabilitar as pessoas, e está relacionado com a intervenção através de equipamentos, procedimentos e relacionamentos que procuram construir uma dimensão mais humanizada nas múltiplas naturezas da produção desse trabalho (OMS, 2020; ESCOLA POLITÉCNICA DE SAUDE JOAQUIM VENÂNCIO, 2006).

O sentido da tecnologia em saúde desdobra-se entre material e imaterial. Merhy classifica a tecnologia em saúde em três aspectos: Dura, Leve-dura e leve. A tecnologia dura está relacionada a utilização de equipamentos, tecnologia leve-dura é aquela que realiza 
procedimentos e protocolos e a tecnologia leve apresenta-se nos processos de acolhimento, vínculos e atenção integral nas ações de saúde (COELHO; JORGE 2009; BRASIL, 2013).

Um dos elementos mais importantes na roda de Terapia Comunitária Integrativa (TCI) é um espaço que produza vínculo, troca e aprendizagem entre os participantes, conseguimos relacionar muitos elementos conceituais da tecnologia leve com a TCI e a construção de uma forma humanizada de ação coletiva que valoriza as subjetividades e propõe autonomia e liberdade.

A Terapia Comunitária Integrativa online foi implantada como um grande desafio; utilizar um meio tecnológico duro como o celular ou o computador (tecnologia dura) mediado pela construção de protocolo (tecnologia leve-dura) para ser utilizada como uma intervenção de tecnologia leve que teve como objetivo utilizar um dos maiores eixos da política nacional de humanização; o acolhimento, a escuta empática, o estabelecimento de vínculos, trocas e compartilhamentos de experiências, num momento onde enfrentamos problemas de ordem global, onde se faz necessário que as pessoas fiquem afastadas para que não transmitam, adoeçam ou morram por contaminação do vírus.

Devido à situação de confinamento, do enfrentamento ao combate do Corona vírus, ou até mesmo do estranhamento dessa nova condição, a população precisou se adaptar, muitas pessoas perderam o vínculo social e deixaram de construir redes de apoio. Desta forma a presença de diversos sentimentos estresse, medo, angústia, conflitos intra e interpessoais foram marcantes e comprometeram a qualidade da saúde mental de muitos cidadãos, atingindo a coletividade de forma significativa.

Além da realização das rodas outro ponto fundamental para gerenciamento do trabalho foi o registro das mesas a fim de avaliar o processo de trabalho, neste sentido estabeleceu-se uma parceria com o SisRodas $^{9}$ (GOIS, 2020).

Nesta parceria o Instituto Afinando Vidas adquiriu o aplicativo para registro de suas rodas presenciais e virtuais. Durante os meses de março, abril, maio, junho e julho de 2020, ao mesmo tempo que foi o Instituto foi apoiando a finalização do documento protocolar da TCI online, também realizou de forma exponencial rodas de terapia online em parceria com outros Polos formadores, bem como prosseguiu com a capacitação em terapia comunitária adaptada

${ }^{9}$ O SisRodas é um Sistema de Registro de Rodas de Terapia Comunitária Integrativa que foi formalmente apresentado no X Congresso Brasileiro e VII Internacional de Terapia Comunitária Integrativa em setembro de 2019. A partir de outubro de 2019 foi iniciado processo de teste para os interessados e em dezembro o Polo Afinando Vidas realizou uma parceria de negócio-financeiro do Polo Instituto Afinando Vidas com o Polo Acreditar e Compartilhar. 
ao formato semipresencial remoto onde os alunos em formação incentivados e supervisionados por seus professores também realizaram rodas.

O Gráfico 1 informa que no período de abril até julho de 2020, foram realizadas 387 rodas de TCI online com a participação de 9457 pessoas, no Brasil. Destacamos aqui a produtividade do Instituto Afinando Vidas que realizou um total de rodas 117 com 1506 participantes, com uma média de 13 participantes por roda, importante destacar que o Instituto Afinando Vidas já utiliza o Sistema desde janeiro de 2020.

Gráfico 1 - Gráfico Rodas de abril a julho 2020

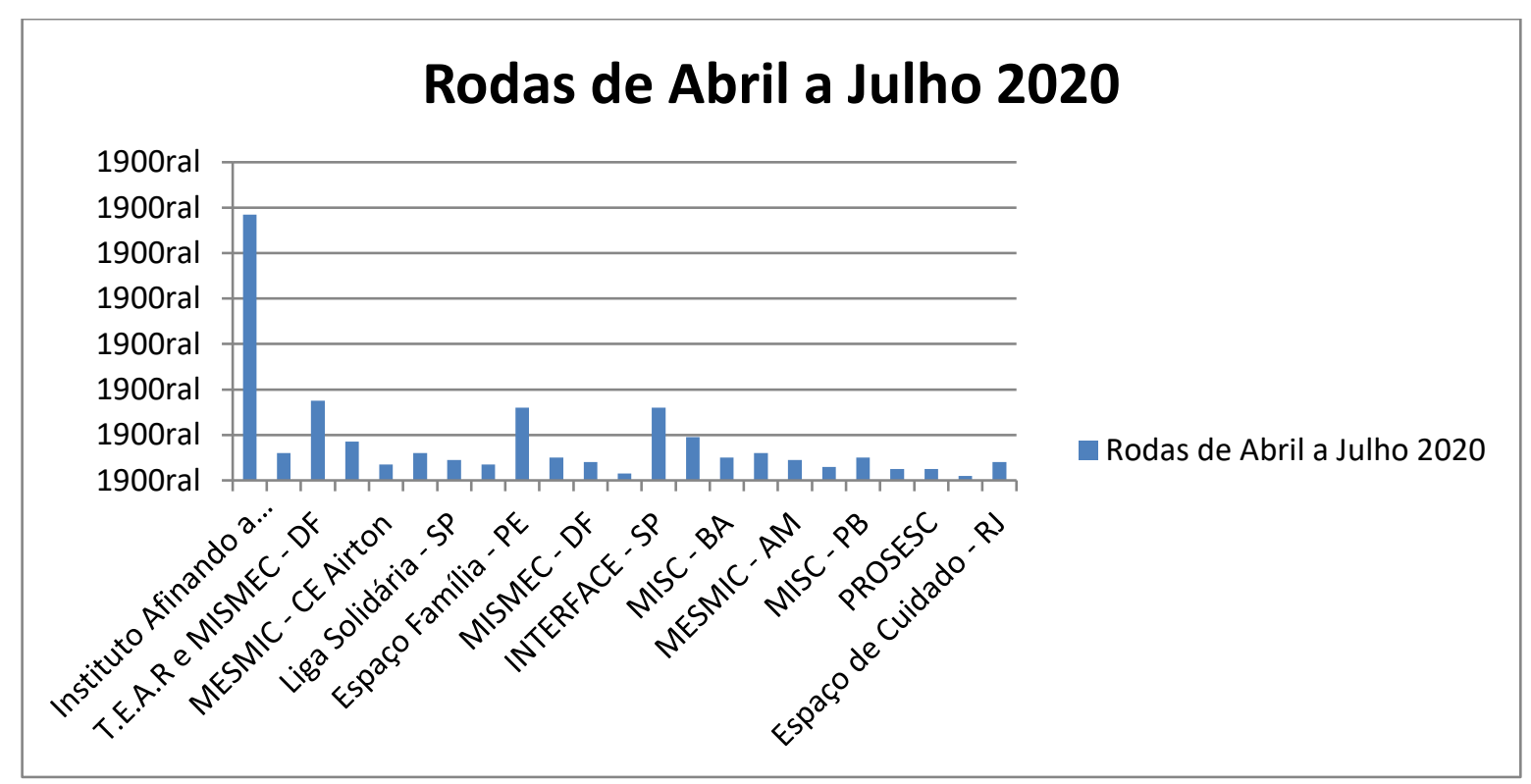

Fonte Sisrodas (2020) - adaptado pelos autores 
Gráfico 2 - Temas mais trabalhados

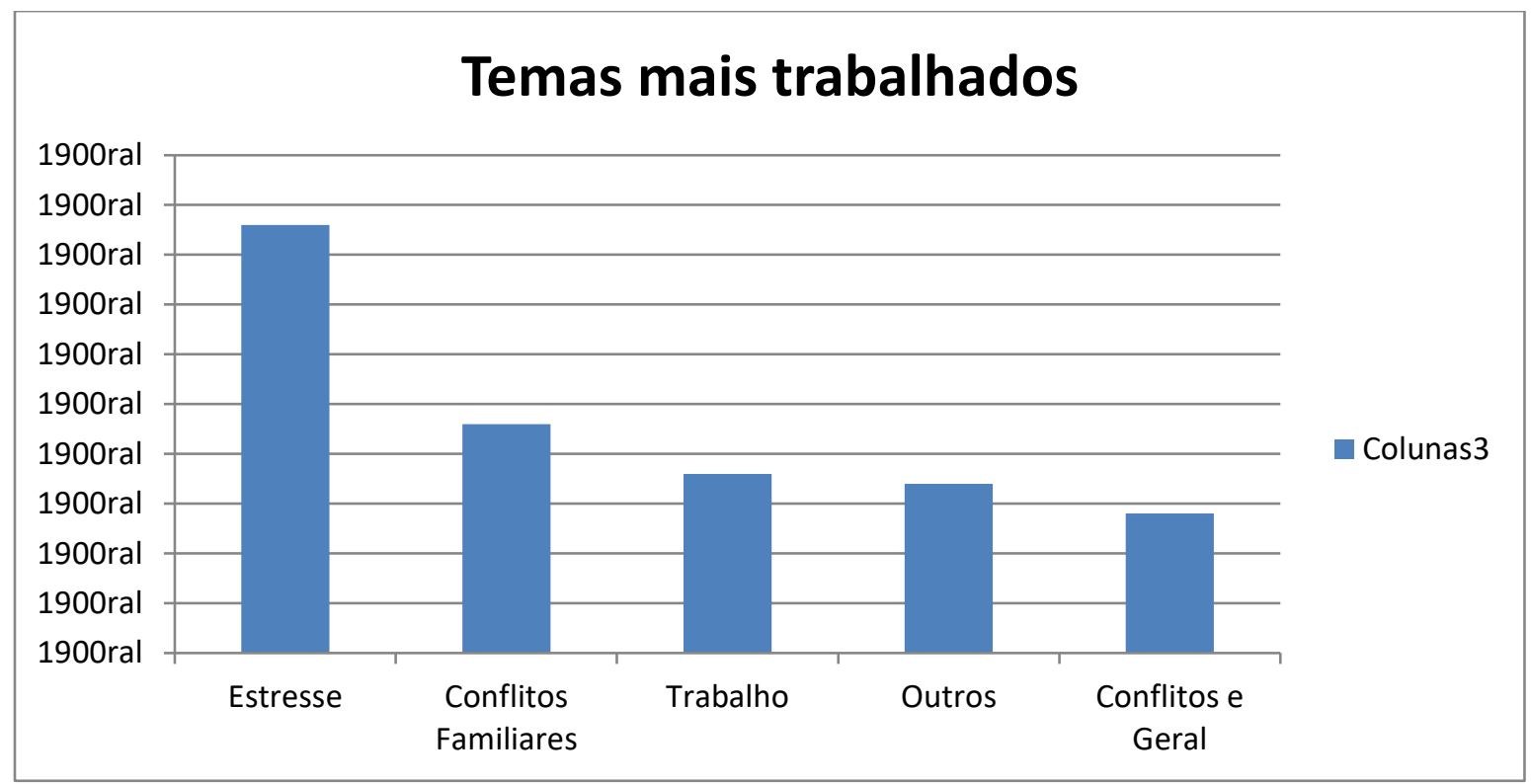

Fonte Sisrodas (2020) - adaptado pelos autores

Gráfico 3 - Subtemas mais trabalhados

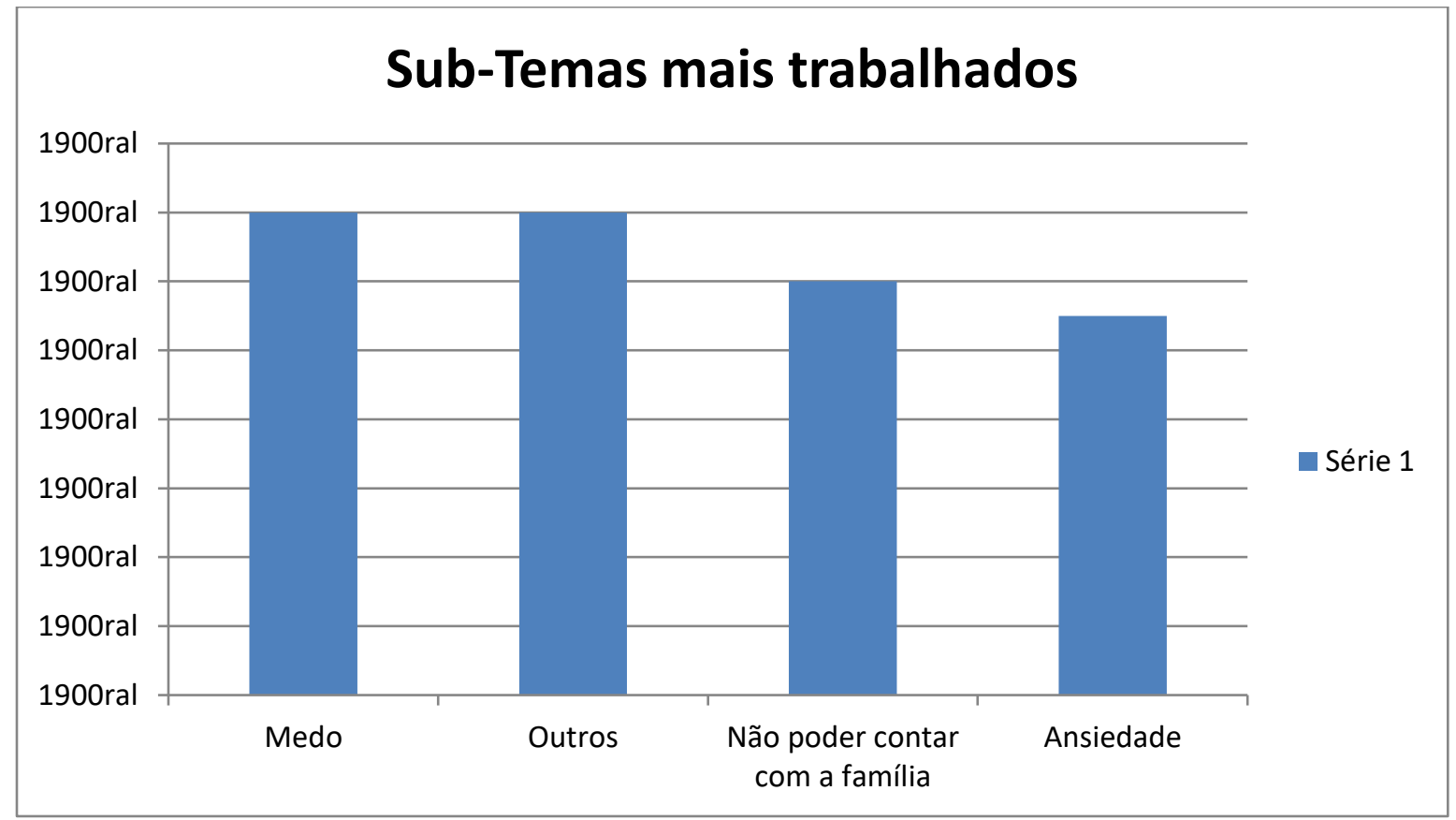

Fonte Sisrodas (2020) - adaptado pelos autores

\section{Discussão}

Conforme os gráficos 2 e 3 é possível observar que os temas que mais se destacaram nas rodas de terapia comunitária online estão relacionados à questões ligadas à pandemia do COVID-19 e a quarentena, sendo estresse, com 43 votos, e suas consequências na saúde mental 
seguido à absorção de informações, como falta de clareza, especialmente relacionados aos diferentes níveis de risco que o indivíduo corre e preocupação em relação a duração da pandemia.

Assim como também conflitos familiares, 23 votos, cujas consequências na saúde mental são medo de ser infectado e ser capaz de infectar alguém. Em relação a falta de trabalho com 18 votos, suas consequências na saúde mental são perdas econômicas, em relação a empregos e adaptação à nova rotina imposta pelo vírus, que acompanha o tédio que causa dependências como distúrbios alimentares - excessos provocados pela ansiedade e pela possível dificuldade de realizar atividade física (especificamente no início da pandemia) e abuso de vícios pré-existentes (drogas lícitas e ilícitas) como forma de aliviar o estresse e a ansiedade.

Quanto aos efeitos psicossociais causados pela pandemia, há uma mudança radical no estilo de vida pela necessidade de rápida adaptação à situação sanitária de saúde, especialmente com a necessidade de redução e distanciamento do contato físico, que para uma cultura latina acaba não sendo fácil deixar os abraços e beijos esse fenômeno de falta de afetividade física também gera estresse.

Portanto a pandemia é, um forte fator de estresse que, por sua vez, é fator causal de desequilíbrios neurofisiológicos. Sobre formas para lidar com a proteção da saúde mental, estão:

- Qualificar a busca de informações sobre a doença e a pandemia.

- $\quad$ Estimular o lado altruísta do indivíduo ao reconhecer que o isolamento faz parte de um comportamento grupal em prol de um benefício social.

- Desenvolver atividades físicas e práticas integrativas complementares de acordo com as condições de saúde.

- Cuidar do equilíbrio da saúde integral.

Em relação a participação nas rodas de TCI, de acordo com relatos dos participantes, muitos informam ter uma melhora no seu estado geral de humor e de estresse ao relatar seus sofrimentos e serem acolhidos (ROCHA, 2013).

\section{Considerações finais}

A experiência da pandemia da COVID-19 tem contribuído com novas percepções na vida da sociedade mundial, muitos aspectos como a vulnerabilidade humana nos fizeram refletir 
sobre nosso modo de viver considerando a dimensão histórica, social, política e avanços e desafios na saúde integral e especificamente considerando a saúde mental, muitas vezes negligenciada. Os esforços das agências nacionais e internacionais de saúde, no início do processo da pandemia no Brasil, apontavam para a travessia do difícil momento que a sociedade passaria, e o comprometimento da saúde integral estaria em jogo, atentava para a busca de estratégias que envolvessem tecnologia e acolhimento coletivo.

A Terapia Comunitária Integrativa online que foi implantada logo no início da pandemia colaborou para transformar o isolamento social em acolhimento emocional, unindo tecnologia leve e os princípios da política nacional de humanização para que os grupos que se encontraram no ambiente virtual pudessem compartilhar seus sofrimentos emocionais e encontrar soluções a partir das experiências de outras pessoas.

A partir dos temas trazidos pelos participantes elencamos quais estratégias de superação este coletivo vem buscando para a superação de suas dificuldades e sofrimentos, são elas: exercícios físicos diários dentro de casa, trabalhos com respiração, como meditação, yoga, mexer na terra para quem está em casa térrea.

Participar das rodas de terapia comunitária online, conforme depoimentos, tem trazido aos participantes a sensação de que não estão sozinhos em seus lares. Observa-se que algumas pessoas participam praticamente todos os dias de rodas online, as mesmas alegam que ficam encorajadas para enfrentar as dificuldades do cotidiano e para suportar o confinamento, além de declararem esperançosos e confiantes de que tudo ficará bem.

Para Barreto et al. (2020), o medo que nos ameaça e se transforma em ansiedade, principalmente quando vemos ou vivemos catástrofes, pode ser transformado, principalmente, quando damos vazão a tensões com atividades prazerosas, quando falamos das emoções com amigos e familiares, assim como quando participamos das rodas de terapia comunitária pois é sabido e é comprovado que "Quando a boca cala o corpo fala, e quando a boca fala o corpo sara" (BARRETO et al., 2020).

O isolamento social ocasionado pela pandemia do COVID-19 tem apresentado importantes desafios e causado um grande impacto na diminuição da qualidade da saúde mental individual e coletiva da sociedade, em especial em determinados grupos populacionais como profissionais da área da saúde, impactando nos principais determinantes sociais em saúde, prejudicando sua própria proteção, promoção, prevenção e recuperação.

Grandes necessidades movimentam muitos saberes em tempos de desafios como o que assistimos, se no passado a descoberta do fogo proporcionou conforto, segurança e sobrevivência aos povos que viviam na caverna, os encontros coletivos realizados através da 
TCI online proporciona conforto emocional, segurança e criatividade no novo normal. Vivemos numa era de problemas globocêntricos e é necessário que os esforços revelem uma mobilização coletiva que resulte numa ética voltada ao protagonismo e ao cuidado coletivo.

A TCI online vem colaborando com o fortalecimento social das relações humanas, e afetivas, aumentando a disposição interna individual e coletiva necessária para atravessar esse momento singular da história da saúde pública mundial.

AGRADECIMENTOS: Todos os terapeutas comunitários espalhados no continente Europeu e Latino Americano. Todos os terapeutas comunitários e colaboradores do Instituto Afinando Vidas, ao Polo Acreditar \& Compartilhar pela organização e disponibilidade dos dados no Sisrodas, a ABRATECOM na pessoa de Josefa Emília Ruiz.

\section{REFERÊNCIAS}

ABRATECOM. Associação Brasileira de Terapia Comunitária Integrativa. 2020.

Disponível em: https://www.abratecom.org.br/. Acesso em: 24 ago. 2020.

\section{ALMEIDA, H. P. Repercussão do Isolamento social na incidência de transtorno do} estresse pós traumático. 2020. Monografia (Trabalho de Conclusão do Curso de Medicina) Universidade Anhembi Morumbi, São Paulo, 2020.

ALVES, R. Tudo sobre o coronavírus - Covid-19: da origem à chegada ao Brasil. Estado de Minas Nacional, 2020. Disponível em:

https://www.em.com.br/app/noticia/nacional/2020/02/27/interna_nacional,1124795/tudosobre-o-coronavirus-covid-19-da-origem-a-chegada-ao-brasil.shtml. Acesso em: 2 set. 2020.

BARRETO A. P. Terapia comunitária: passo a passo. 5. ed. Fortaleza: LCR, 2019.

BARRETO, A. et al. Integrative Community Therapy in the Time of the New Coronavirus Pandemic in Brazil and Latin America. World Soc Psychiatry, v. 2, n. 2, p. 103-105, 2020. Disponível em: http://www.worldsocpsychiatry.org/temp/WorldSocPsychiatry221037349955_202459.pdf. Acesso em: 28 set. 2020.

BRASIL. Política Nacional de Humanização. 1. ed. 1 reimp. Brasília, 2013. Disponível em: http://bvsms.saude.gov.br/bvs/publicacoes/politica_nacional_humanizacao_pnh_folheto.pdf. Acesso em: 20 ago. 2020.

BRASIL. Ministério da Saúde. Secretaria de Atenção à Saúde. Departamento de Atenção Básica. Manual de implantação de serviços de práticas integrativas e complementares no SUS. Brasília, DF: Ministério da Saúde, 58 p., 2018.

COELHO, M. O.; JORGE, M. S. B. Tecnologia das relações como dispositivo do atendimento humanizado na atenção básica à saúde na perspectiva do acesso, do acolhimento 
e do vínculo. Ciência \& Saúde Coletiva, v. 14, supl. 1, p. 1523-1531, 2009. Disponível em: https://www.scielo.br/pdf/csc/v14s1/a26v14s1.pdf. Acesso em: 15 ago. 2020.

CORREA, H. A saúde mental em xeque. Associação médica de Minas Gerais, abr. 2020. Disponível em: https://ammg.org.br/noticia/artigo-humberto-correa/. Acesso em: 02 set. 2020.

CRISTOPH, A. Psicología del miedo: temores, angustias y fobias. 5. ed. Barcelona: Kairos, 2010.

DAUMAS P. R. et al. O Papel da Atenção Primária na Rede de Atenção à Saúde no Brasil Limites e Possibilidades no Enfrentamento da covid-19. Cadernos de Saúde Pública, Rio de Janeiro, v. 36, n. 6, jul. 2020. Disponível em: http://cadernos.ensp.fiocruz.br/csp/artigo/1093/. Acesso em: 23 ago. 2020.

ECCARD, A. F. C. Ensaios Filosóficos. 2018. Disponível em: www.ensaiosfilosoficos.com.br. Acesso em: 29 abr. 20

ESCOLA POLITÉCNICA DE SAUDE JOAQUIM VENÂNCIO. Dicionário da educação profissional em saúde. Rio de Janeiro: EPSJV, 308 p., 2006. ISBN 85-98768-16-2.

GOIS, M. M. J. Relatório de utilização do SisRodas: Sistema de Registro de Rodas de Terapia Comunitária Integrativa. Curitiba, PR, 2020. Disponível em: http://acreditarecompartilhar.com.br/rodas/. Acesso em: 2 set. 2020.

MORENS D. M. et al. Emerging infections: a perpetual challenge. Lancet Infect Dis., v. 8, n. 11, p. 710-719, nov. 2008. Disponível em:

https://www.ncbi.nlm.nih.gov/pmc/articles/PMC2599922/. Acesso em: 25 maio. 2020.

OMS. ORGANIZAÇÃO MUNDIAL DA SAÚDE. Folha informativa COVID-19 -

Escritório da OPAS e da OMS no Brasil. 2020. Disponível em:

https://www.paho.org/pt/covid19. Acesso em: 23 ago. 2020.

OPAS. ORGANIZAÇÃO PAN-AMÉRICA DE SAÚDE. Folha informativa COVID-19 Escritório da OPAS e da OMS no Brasil. 2020. Disponível em: https://www.paho.org/pt/covid19. Acesso em: 2 set. 2020.

ORNELL, F. Pandemia de medo e Covid-19: impacto na saúde mental e possíveis estratégias. Braz. J. Psychiatry, v. 42, n. 2, p. 232-5, 2020. Disponível em: https://d494f813-3c95-463a898c-ea1519530871.filesusr.com/ugd/c37608_a7ff70b1615f4ffcbc7d672de1822add.pdf. Acesso em: 02 set. 2020.

REARDON, S. Ebola's mental-health wounds linger in Africa: health-care workers struggle to help people who have been traumatized by the epidemic. Nature, v. 519, n. 7541, 2015.

REZENDE, J M À sombra do plátano: crônicas de história da medicina [online]. São Paulo: Editora Unifesp, 2009. Disponível em: http://books.scielo.org/id/8kf92. Acesso em: 2 set. 2020.

ROCHA, I. A. Terapia comunitária integrativa: situações de sofrimento emocional e estratégias de enfrentamento apresentadas por usuários. Rev. Gaúcha Enferm., Porto Alegre, 
v. 34, n. 3, p. 155-162, set. 2013. Disponível em

http://www.scielo.br/scielo.php?script=sci_arttext\&pid=S1983-

$14472013000300020 \& \operatorname{lng}=$ pt\&nrm=iso. Acesso em: 02 set. 2020.

SANAR. Pandemias na História: o que há de semelhante e de novo na Covid-19. 2020.

Disponível em: https://www.sanarmed.com/pandemias-na-historia-comparando-com-a-covid19. Acesso em: 29 abr. 2020.

SHALDERS, A. Quais são as principais medidas do governo brasileiro contra o Coronavírus até agora? BBC News Brasil, 2020. Disponível em: https://www.bbc.com/portuguese/brasil51889723. Acesso em: 02 set. 2020.

SHIGEMURA, J. et al. Respostas públicas ao novo coronavírus 2019 no Japão: consequências para a saúde mental e populações-alvo. Psychiatry and Clinical Neurosciences, v. 74, n. 4, p. 281-282, 2020. Disponível em:

https://onlinelibrary.wiley.com/doi/full/10.1111/pcn.12988. Acesso em 02 set. 20. DOI: https://doi.org/10.1111/pcn.12988

SUPER INTERESSANTE. As grandes epidemias da história. 2004. Disponível em: https://super.abril.com.br/saude/as-grandes-epidemias-ao-longo-da-historia/. Acesso em: 29 abr. 2020.

\section{Como referenciar este artigo}

SILVA, A. L. P.; OTAVIANO, D.; FERREIRA, F. C. V.; OTAVIANO, J. V.; OTAVIANO, J.; OLIVEIRA, N.; DONIZETE, W. P. Implantação de Terapia Comunitária online: tecnologia do cuidado em tempos de pandemia. Temas em Educ. e Saúde, Araraquara, v. 16, n. esp. 1, p. 393-408, set., 2020. e-ISSN 2526-3471. DOI: https://doi.org/10.26673/tes.v16iesp.1.14319

Submetido em: 20/05/2020

Revisões requeridas: $30 / 05 / 2020$

Aprovado em: 25/08/2020

Publicado em: 30/09/2020 